BULLETIN Bulletin hispanique

HISPANIQUE Université Michel de Montaigne Bordeaux

$115-2$ | 2013

Les traductions vieillissent-elles ?

\title{
Dolores Thion Soriano-Mollá (ed.), El costumbrismo,
} nuevas luces

PUPPA, Presses de l'Université de Pau et des Pays de l'Adour, Pau, 2013

\section{Blanca Ripoll Sintes}

\section{OpenEdition}

\section{Journals}

Edición electrónica

URL: http://journals.openedition.org/bulletinhispanique/2944

DOI: 10.4000/bulletinhispanique.2944

ISSN: $1775-3821$

\section{Editor}

Presses universitaires de Bordeaux

\section{Edición impresa}

Fecha de publicación: 28 diciembre 2013

Paginación: 777-781

ISBN: 978-2-86781-908-7

ISSN: 0007-4640

\section{Referencia electrónica}

Blanca Ripoll Sintes, «Dolores Thion Soriano-Mollá (ed.), El costumbrismo, nuevas luces », Bulletin hispanique [En línea], 115-2 | 2013, Publicado el 14 febrero 2014, consultado el 23 septiembre 2020. URL : http://journals.openedition.org/bulletinhispanique/2944 ; DOI : https://doi.org/10.4000/ bulletinhispanique.2944

Este documento fue generado automáticamente el 23 septiembre 2020.

Tous droits réservés 


\title{
Dolores Thion Soriano-Mollá (ed.), El costumbrismo, nuevas luces
}

PUPPA, Presses de l'Université de Pau et des Pays de l'Adour, Pau, 2013

\author{
Blanca Ripoll Sintes
}

\section{REFERENCIA}

Dolores Thion Soriano-Mollá (ed.), El costumbrismo, nuevas luces. PUPPA, Presses de

l'Université de Pau et des Pays de l'Adour, Pau, 2013, 640 pp. - ISBN 978-2-35311-032-2.

1 Revisar un concepto asumido por todos. Iluminarlo de nuevo desde la filología y la teoría literaria del siglo XXI. Estos son los objetivos generales de este volumen, cuidadosamente editado por la profesora Thion desde la Université de Pau et des Pays de l'Adour, que se concretan desde el prólogo escrito por Leonardo Romero Tobar hasta la última colaboración de las 38 que integran El costumbrismo, nuevas luces.

El profesor de Zaragoza, Romero Tobar, abre el libro con una exhaustiva revisión de la presencia lexicográfica y bibliográfica del concepto «costumbrismo», a la vez que cuestiona los matices -frecuentemente peyorativos- que la noción ha ido adquiriendo con el paso de los años. Recoge en este prólogo la voluntad que animó al proyecto de la profesora Thion: revisar diacrónicamente el costumbrismo en la literatura española y ampliar semánticamente el concepto, de modo que «costumbrismo» ya no sea algo privativo exclusivamente del siglo XIX, como el lector podrá comprobar en los textos dedicados a Javier Marías, Manuel Longares y Bernardo Atxaga, entre otros.

3 En consecuencia, el marco cronológico escogido (desde el siglo XVIII hasta el XX-XXI) obliga a estructurar temática e históricamente las contribuciones de este volumen, que se divide en dos grandes bloques y cuatro subapartados. La primera parte, dedicada al Siglo XIX, presenta la sección «El costumbrismo: concepto, perspectivas e implicaciones», donde se analiza la noción de costumbrismo desde la óptica de la teoría de la literatura y desde sus orígenes históricos, a partir del análisis filológico de textos de Ramón de la Cruz, Bretón de los Herreros, Larra, Manuel Matoses o Mesonero 
Romanos. A continuación, la perspectiva transfronteriza gobierna el segundo subapartado del bloque decimonónico: «De Europa y América: miradas cruzadas», sección que mayoritariamente se centra en la plasmación de las costumbres a partir de las crónicas de viajes. Se cierra el Siglo XIX con el subapartado «Pervivencias del Costumbrismo» en el que los autores se dedican a estudiar la herencia costumbrista que recogieron y actualizaron los novelistas españoles de la segunda mitad del siglo XIX (Benito Pérez Galdós, Emilia Pardo Bazán, Armando Palacio Valdés, Rafael Altamira o Vicente Blasco Ibáñez). El segundo y último bloque se titula «Siglo XX. Herencias costumbristas y representaciones modernas de la costumbre»; en él se dan la mano contribuciones sobre autores diversos como Salvador Rueda, José Martínez Ruiz, Francisco Umbral, José Martín Recuerda o los ya citados Javier Marías, Manuel Longares y Bernardo Atxaga.

4 Los profesores Joaquín Álvarez Barrientos y Luis Beltrán Almería dan los primeros compases de apertura del primer gran capítulo del libro. Álvarez Barrientos recoge las contradicciones existentes entre los escritores costumbristas (se apoya en Larra y Mesonero), que reivindicaron su nexo con la modernidad europea (Addison), y el análisis que del costumbrismo hicieron los historiadores de la literatura del siglo XIX, desde una óptica nacionalista más conservadora. Y de la historiografía literaria, a la teoría de la literatura: el profesor Beltrán Almería analiza la singularidad de la noción de costumbrismo en el campo de la filología española respecto de otras filologías europeas y señala ciertas vaguedades que tradicionalmente se han acumulado en la definición filológica española de costumbrismo, como la indefinición del concepto de «costumbre» o el trasvase entre periodismo y novela.

5 A continuación, se nos proporcionan diversas miradas hacia los orígenes del costumbrismo literario español: Mireille Coulon selecciona fragmentos de sainetes de Ramón de la Cruz que claramente muestran la reproducción satírica de costumbres, como La Plaza Mayor (1765), La pradera de San Isidro (1766) o El Rastro por la mañana (1770); Miguel Ángel Muro estudia cómo la comedia de costumbres de Bretón de los Herreros se centra, al igual que algunos textos de Mesonero y Larra, en la clase media y en la sátira («suave») de algunos de sus hábitos; y después de revisar cómo se articula la noción de pintoresquismo en la Europa del siglo XIX, Antonio Dorca expone el costumbrismo pintoresco de Mesonero Romanos, especialmente a partir del estudio del texto «La posada o España en Madrid».

6 Larra tenía que ser un hito ineludible en un volumen dedicado al costumbrismo. El profesor José María Ferri Coll abre su artículo con la voluntad manifiesta de Larra de ser expresión «del progreso intelectual del siglo»-no en vano es el padre del periodismo contemporáneo: Ortega, D'Ors y tantos otros buscarían captar el espíritu de su tiempo, las «palpitaciones» de su época-. Excelente marbete para un texto que señala cómo Fígaro quiso analizar las contradicciones íntimas de la realidad, pero desde un tiempo muy temprano supo ver los lastres de la retórica costumbrista y quiso desligarse de ella.

7 Después de Larra, forzosamente debemos detenernos en los vínculos que unen prensa y cuadro de costumbres. A la revisión exhaustiva y pormenorizada del periodismo (revistas, periódicos) satírico-costumbrista español que Enrique Miralles enmarca en el período del reinado de Isabel II (1843-1868), se suma la imprescindible contribución del profesor Enrique Rubio Cremades, quien rescata de entre la enorme multitud de periodistas del segundo tercio del siglo XIX a Manuel Matoses y analiza la recopilación 
de cuadros de costumbres Del montón. Retratos de sujetos que se ven en todas partes (1887), que se caracteriza por el predominio del tipo frente a la escena, por la captación de nuevos personajes (Matoses se adapta a los cambios sociológicos que observa a su alrededor) y por la crítica social que subyace en su obra.

Cabe destacar, a continuación, el capítulo de Borja Rodríguez Gutiérrez, que señala la existencia de una propuesta ético-estética concreta dentro del marbete general del costumbrismo: el «costumbrismo negro», óptica más oscura, amarga y pesimista, que ejemplifica con el análisis de diversos artículos localizados en la prensa de la época. El profesor Rodríguez observa cómo la estilización negativa de la representación de la realidad del costumbrismo negro le impide entrar dentro de la mímesis costumbrista canónica y lo enlaza certeramente con un río que a veces asoma y a veces se esconde a lo largo y ancho de la historia de la literatura española: el «tremendismo» que va desde la literatura popular medieval hasta la novela del siglo XX, pasando por Quevedo o Valle-Inclán.

9 Carmen Servén Díez analiza los textos costumbristas de escritoras menores del siglo XIX (al amparo de Böhl de Faber, Gómez de Avellaneda o Pardo Bazán), como Rosario de Acuña, Robustiana Armiño de Cuesta, Emilia Calte y Torres de Quintero, Pilar Contreras y Alba de Rodríguez o Sarah Lorenzana; y también desde una perspectiva cercana a los estudios de género, María de los Ángeles Rodríguez Sánchez cierra este bloque con el estudio de la actriz como tipo de los artículos de costumbres de los escritores del siglo XIX.

10 La profesora Ana María Freire López da inicio al apartado «De Europa y América: miradas cruzadas» con el estudio de las sinergias entre literatura de viajes y costumbrismo desde un punto de vista lexicográfico. Seguidamente, el lector se encuentra ante diversas contribuciones que recogen el quehacer tanto de viajeros extranjeros en España, como de viajeros españoles por el mundo, en cuyos textos la mirada asombrada ante lo nuevo se traduce en una visión costumbrista, estática, de la realidad. Así, Jesús Rubio trata la labor relevante que el pintor sevillano José Domínguez Bécquer, del primer tercio del XIX, llevó a cabo con sus pequeños cuadros llamados «figurines de costumbres» para la creación de una imagen pintoresca, romántica, de Andalucía en el extranjero, gracias a sus frecuentes contactos con los numerosos viajeros que transitaban por el consulado británico de Sevilla. Por su parte, el profesor Salvador García Castañeda muestra, a partir del análisis de parte de la correspondencia personal de Washington Irving desde la España de Isabel II, las escenas costumbristas, pintorescas, que Irving compartió con sus allegados a propósito de sus vivencias en la corte isabelina.

11 En cuanto a la recepción de esta imagen pintoresca y romántica de España en el extranjero, hallamos dos contribuciones importantes. En primer lugar, Jean-René Aymes expone el tratamiento costumbrista de la imagen de España en dos publicaciones francesas del segundo tercio del siglo XIX: el Magasin Universel (1833-1839) y el Magasin Pittoresque (1833-1860). Y a continuación, la editora del volumen y responsable de la iniciativa académica que dio lugar al libro, Dolores Thion Soriano-Mollá recupera del olvido de la historiografía francesa a Victor-Joseph Étienne Jouy, uno de los modelos más influyentes en la evolución del costumbrismo español, y en un interesante y riguroso planteamiento, cuestiona la supuesta relación entre Madrid (1825) y la figura del escritor francés, que aparece como director de la colección en que se publicó el libro (probablemente como señuelo editorial, dada la enorme 
importancia de Jouy como configurador del género costumbrista en Francia). Por otra parte, la profesora Renata Londero analiza el costumbrismo avant-la-lettre de José María Blanco White en sus recuerdos nostálgicos de la patria lejana, así como en sus crónicas periodísticas sobre la Inglaterra que le acogió.

En una segunda serie de contribuciones, podemos señalar la óptica transatlántica que las preside. Montserrat Becerril estudia los textos de la escritora sueca Fredrika Bremer, quien en su segundo viaje a Estados Unidos en 1851, desembarcó en Cuba desde donde expondrá en cartas y crónicas su compleja visión de la sociedad de la isla, con especial atención a los grupos sociales más marginados. Eva Lafuente trata la representación costumbrista de tipos extranjeros (americanos, en especial) para el público mayoritariamente peninsular en Los españoles, americanos $y$ lusitanos pintados por sí mismos (1882). Y Rocío Charques Gámez muestra, a partir de la obra Tipos y paisajes criollos (1901-1903), las crónicas costumbristas de la sociedad argentina que publicó el escritor de origen francés Godofredo Daireaux.

Asimismo, podemos señalar estudios del costumbrismo al otro lado del océano, como la contribución de Anne-Marie Brenot a propósito de la novela Cecilia Valdés o la Loma del Ángel (1882) del escritor cubano Cirilo Villaverde; o el estudio comparativo de Raquel Gutiérrez Sebastián sobre el arquetipo del indiano en la obra del cántabro José María de Pereda y en la del cubano Ramón Meza: ambos arrancan de la configuración costumbrista y hacen uso de técnicas propias de la escritura costumbrista para la caracterización de sus personajes.

14 A continuación, se da comienzo al apartado «Pervivencias del costumbrismo», que podríamos sintetizar en una definición de Montesinos de la que la profesora Sotelo parte en su estudio: el costumbrismo como eslabón necesario para alcanzar la gran novela realista decimonónica, de modo que este capítulo establecerá las necesarias correlaciones entre costumbrismo y realismo-naturalismo. En esta línea, se suceden las contribuciones de esta sección. Cristina Patiño Eirín analiza comparativamente la obra de Jacinto Salas y Quiroga, autor coruñés, gran cronista del Madrid del primer tercio del XIX, y la del novelista canario Benito Pérez Galdós, que se serviría de la España retratada por Salas y Quiroga para configurar la intrahistoria de algunos de sus Episodios. Marisa Sotelo Vázquez revela las herencias y diferencias del costumbrismo galdosiano frente al costumbrismo canónico; diferencias que estriban en la oposición entre mirada estática (costumbrismo) y mirada dinámica (novela realista), a propósito del Episodio Nacional de la tercera serie La estafeta romántica (1899). A continuación, Ermitas Penas Varela estudia las relaciones entre costumbrismo y novela en la obra galdosiana Fortunata y Jacinta (1886-87), que se centran fundamentalmente en las descripciones de las calles madrileñas, de algunos tipos y ciertas técnicas narrativas, si bien Galdós rebasa todos los límites de la retórica costumbrista y logra una representación dinámica y multiperspectivista de la vida en su ficción novelesca.

Cambiando de tercio y de autor, el profesor José Manuel González Herrán analiza el costumbrismo -como en Galdós- que se halla en su gran mayoría en las descripciones ambientales de la novela de Armando Palacio Valdés El cuarto poder, Novela de costumbres (1888). María de los Ángeles Ayala muestra un análisis exhaustivo de los tipos y escenas costumbristas en el corpus de la obra narrativa del alicantino Rafael Altamira, quien se propuso describir los usos y costumbres de sus paisanos en novelas, cuentos y artículos, como se lo propondría también el valenciano Vicente Blasco Ibáñez; Elisabeth Delrue estudia cómo la herencia costumbrista como técnica descriptiva se pone al servicio, en 
Blasco, de su proyecto ético-estético (la sátira de costumbres sociales y políticas). Montserrat Ribao Pereira recoge dos tipos costumbristas (el de la modista y el de la areana o aureana -buscadora de oro gallega) en dos obras teatrales de Emilia Pardo Bazán, El vestido de boda (1898) y La suerte (1904); tipos que sirven de arranque puesto que la escritora coruñesa logra crear personajes dinámicos, con entidad propia. Por último, destacaremos la novedosa conjunción entre la ciencia ficción y el costumbrismo que Juan Molina Porras observa en los relatos breves de Nilo María Fabra: Por los espacios imaginarios (con escalas en la tierra), de 1885; Cuentos ilustrados (1895); y Presente y futuro (1897).

Finalicemos ya esta reseña dando cuenta del último apartado del volumen: «Siglo XX: Herencias costumbristas y representaciones modernas», que se abre con el estudio de Daniel-Henri Pageaux sobre el costumbrismo descriptivo, tanto de la vida estudiantil en Madrid, como en Santiago de Compostela, en La casa de la Troya (1915) de Alejandro Pérez Lugín. María Isabel Jiménez Morales contempla la poco estudiada prosa costumbrista-modernista de Salvador Rueda (El patio andaluz, de 1886, y El cielo alegre, de 1887), en la que se observa la particular suma de plasmación de costumbres y retórica finisecular colorista y opulenta. El profesor Christian Manso teje un tapiz comparativo a partir de las figuras de Ortega y Gasset, José Martínez Ruiz y Gustave Courbet, en torno a posibles afinidades entre el escritor valenciano y el pintor francés a propósito de la pintura (sobre el lienzo o sobre el papel) de escenas de costumbres. Bénédicte de Buron-Brun revisa la mirada de Francisco Umbral sobre Mesonero y Larra, y señala cómo las crónicas umbralianas recogen el guante de la visión crítica y poliédrica de Fígaro y se escapan de la escena estática de Mesonero. Béatrice Bottin trata el costumbrismo ambiental con que el dramaturgo granadino José Martín Recuerda buscaba transmitir a su público sensación de autenticidad, de verdad dramática. Y ya en el marco de la democracia, J. Ignacio Díez propone replantear la posibilidad de conjugar autoficción y costumbrismo posmoderno en la novela de Javier Marías Todas las almas (1989); José Antonio Escrig analiza la actualización del costumbrismo en la obra de Manuel Longares; y Ur Apalategui expone el hilo vertebrador del costumbrismo literario vasco en el diálogo entre la obra de Pierre Loti, Ramuntxo (1897), y la de Bernardo Atxaga.

El costumbrismo, nuevas luces acaba con una recopilación de resúmenes escritos en francés de cada una de las contribuciones, cuestión que señala la evidente voluntad internacionalizadora del proyecto. 